\title{
Electroluminescent properties of Tb-doped carbon-enriched silicon oxide
}

\author{
S.I. Tiagulskyi ${ }^{1}$, A.N. Nazarov ${ }^{1}$, S.O. Gordienko ${ }^{1}$, A.V. $\operatorname{Vasin}^{1}$, A.V. Rusavsky ${ }^{1}$, T.M. Nazarova ${ }^{2}$, \\ Yu.V. Gomeniuk ${ }^{1}$, G.V. Rudko ${ }^{1}$, V.S. Lysenko ${ }^{1}$, L. Rebohle ${ }^{3}$, M. Voelskow ${ }^{3}$, W. Skorupa ${ }^{3}$, Y. Koshka ${ }^{4}$ \\ ${ }^{1}$ Lashkaryov Institute of Semiconductor Physics, National Academy of Sciences of Ukraine, \\ 45, prospect Nauky, 03028 Kyiv, Ukraine \\ ${ }^{2}$ Department of Common and Inorganic Chemistry, National Technical University of Ukraine “KPI”, Kyiv, Ukraine \\ ${ }^{3}$ Institut für Ionenstrahlphysik und Materialforschung, \\ Helmholtz Zentrum Dresden-Rossendorf e.V., Dresden, Germany \\ ${ }^{4}$ Department of Electrical and Computer Engineering, Mississippi State University, \\ P.O. Box 9571, Mississippi 39762, USA \\ Phone/fax:+38(044) 52561 77; e-mail:nazarov@lab15.kiev.ua
}

\begin{abstract}
An electroluminescent device utilizing a heterostructure of amorphous terbium doped carbon-rich $\mathrm{SiO}_{\mathrm{x}}\left(\mathrm{a}-\mathrm{SiO}_{\mathrm{x}}: \mathrm{C}: \mathrm{Tb}\right)$ on silicon has been developed. The $\mathrm{a}-\mathrm{SiO}_{\mathrm{x}}: \mathrm{C}: \mathrm{Tb}$ active layer was formed by $\mathrm{RF}$ magnetron sputtering of $\mathrm{a}-\mathrm{SiO}_{1-\mathrm{x}}: \mathrm{C}_{\mathrm{x}}: \mathrm{H}(: \mathrm{Tb})$ film followed by high-temperature oxidation. It was shown that, depending on the polarity of the applied voltage, the electroluminescence is either green or white, which can be attributed to different mechanisms of current transport through the oxide film - space charge limited bipolar double injection current for green electroluminescence and trap assisted tunneling or Fowler-Nordheim tunneling for white electroluminescence.
\end{abstract}

Keywords: electroluminescence, a-SiO: $\mathrm{C} / \mathrm{Si}$ heterostructure, $\mathrm{Tb}, \mathrm{RF}$ magnetron sputtering, charge transport mechanisms.

Manuscript received 25.11.13; revised version received 23.01.14; accepted for publication 20.03.14; published online 31.03.14.

\section{Introduction}

Silicon photonics is attractive field of the research in recent decades that is associated with integration of photonic component in silicon (Si) microelectronics $[1,2]$. Special attention is attracted by silicon-based switchable devices that can change colour (wavelength) of light emission by changing either applied electric field [3] or bias polarity [4, 5]. Usually, for such kind devices $\mathrm{SiO}_{2}-\mathrm{Si}$ structures are used with the oxide doped with rear-earth impurities [3] or enriched with Si nanocrystals [5], which results in colour changing from red to blue in the former case and from red to infra-red in the latter one. Recently, it was demonstrated that silicon oxycarbide by itself can efficiently emit white photo$[6,7]$ and electroluminescence [8]. On the other hand, embedding rear-earth (RE) metals into silicon oxycarbide resulted in a more significant increase of photoluminescence (PL) intensity at wavelengths corresponding to intra- $4 f$ shell transitions of the impurity in comparison with the PL intensity at the same wavelengths for the RE embedded in $\mathrm{SiO}_{2}$ matrix [9]. In this paper, for the first time a light-emitting device based on $\mathrm{Tb}$ doped carbon-rich silicon oxide/silicon heterostructure, which can emit green light at the forward bias and white light at the reverse one, is considered. Parameters of the light emission and current transfer mechanisms are studied.

\section{Sample preparation and methods of research}

The first step in fabrication of the electroluminescent structure was to deposit a $-\mathrm{SiO}_{1-\mathrm{x}}: \mathrm{C}_{\mathrm{x}}: \mathrm{H}(: \mathrm{Tb})$ thin films on $\mathrm{Si}(100)$ ( $p$-type, $40 \mathrm{Ohm} \cdot \mathrm{cm})$ wafer by reactive radio- 
frequency magnetron sputtering of a polycrystalline $\mathrm{SiC}+\mathrm{Tb}$ targets in $\mathrm{Ar}\left(96\right.$ vol.\%) $+\mathrm{CH}_{4}(4$ vol.\%) gas mixture. The substrate temperature was about $200{ }^{\circ} \mathrm{C}$. The thickness of the $\mathrm{a}-\mathrm{SiO}_{1-\mathrm{x}}: \mathrm{C}_{\mathrm{x}}: \mathrm{H}(: \mathrm{Tb})$ layer was $750 \mathrm{~nm}$. After deposition, the samples were annealed in dry oxygen for $15 \mathrm{~min}$ within the temperature range 450 to $700{ }^{\circ} \mathrm{C}$.

The chemical composition and interatomic bonds were analyzed using Fourier-transform infrared (FTIR) transmittance spectroscopy (2000FT-IR, Perkin Elmer), electron energy-loss spectroscopy (EELS) (JEM2100, Jeol Co.), and Rutherford back-scattering spectroscopy (RBS) at the Rossendorf Van-de-Graaf accelerator, using $1.7 \mathrm{MeV} \mathrm{He}^{+}$ions as incident particles and backscattering angle $170^{\circ}$.

Photoluminescence (PL) spectra were measured at room temperature using typical PL setup with excitation by LED with 375-nm excitation wavelength. The maximum PL intensity was observed after annealing at $600{ }^{\circ} \mathrm{C}$, and the corresponding samples were selected for the fabrication of the electroluminescent device.

For electroluminescence (EL) and the electrical measurements, an Au circular ring gate with ultrathin semi-transparent inner part was deposited on the oxidized $\mathrm{a}-\mathrm{SiO}_{1-\mathrm{x}}: \mathrm{C}_{\mathrm{x}}: \mathrm{H}(: \mathrm{Tb})$ film, and an $\mathrm{Al}$ layer was deposited on the back side of the silicon substrate (see inset in Fig. 1). The EL spectra were measured under a constant current for the forward and reverse regimes of the applied voltage at room temperature. A negative voltage applied to the gate electrode corresponded to the forward-bias regime, and a positive voltage - to the reverse-bias regime. The EL intensity (ELI) versus the applied voltage was measured together with the current-voltage $(I-V)$ characteristics by using a Keithley 2410 high voltage sourcemeter. The EL signal from the samples was collected with a Triax 320 monochromator and detected by a photomultiplier (Hamamatsu H7732-100).

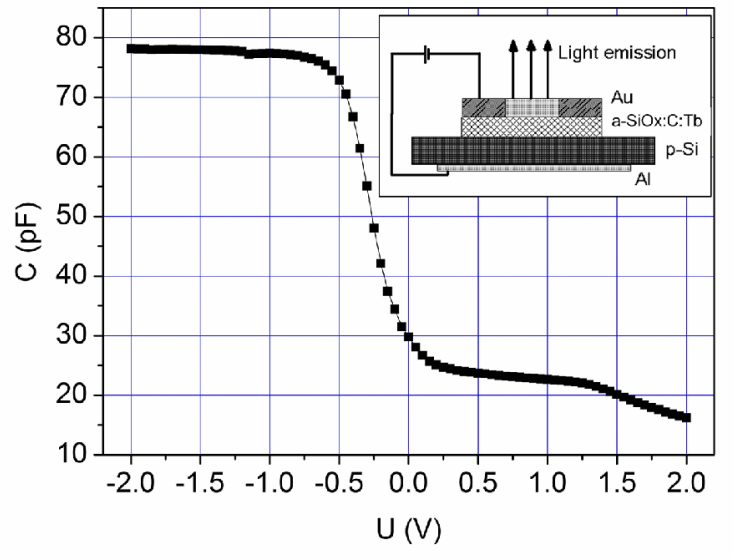

Fig. 1. Capacitance-voltage characteristic for the $\mathrm{a}-\mathrm{SiO}_{\mathrm{x}}: \mathrm{C}: \mathrm{Tb} / \mathrm{p}-\mathrm{Si}$ heterostructure. Inset: the schematic view of the used devices.
High-frequency (1 MHz) capacitance-voltage $(C-V)$ characteristics were measured using precision LCR meter Agilent 4284A at room temperature.

\section{Experimental results}

\subsection{Chemical composition}

\subsubsection{FTIR}

Transmittance spectra of as-deposited and oxidized $\mathrm{a}-\mathrm{SiO}_{1-\mathrm{x}}: \mathrm{C}_{\mathrm{x}}: \mathrm{H}(: \mathrm{Tb})$ films are presented in Fig. 2. The spectrum from as-deposited $\mathrm{a}-\mathrm{SiO}_{1-\mathrm{x}}: \mathrm{C}_{\mathrm{x}}: \mathrm{H}(: \mathrm{Tb})$ contains several absorption bands within the spectral range 400 to $4000 \mathrm{~cm}^{-1}$. Two main absorption bands are at 780 and $1000 \mathrm{~cm}^{-1}$. The first one is due to $\mathrm{Si}-\mathrm{C}$ stretching vibration with possible minor contribution from $\mathrm{CH}_{3}$ rocking in $\mathrm{Si}-\mathrm{CH}_{3} \quad\left(780 \mathrm{~cm}^{-1}\right)$ and $\mathrm{Si}-\left(\mathrm{CH}_{3}\right)_{2}\left(800 \mathrm{~cm}^{-1}\right)$ [10-13]. The absorption band at $1000 \mathrm{~cm}^{-1}$ in $\mathrm{a}-\mathrm{SiO}_{1-\mathrm{x}}: \mathrm{C}_{\mathrm{x}}: \mathrm{H}$ films is commonly ascribed to rocking/waging vibration modes in $\mathrm{CH}_{2}$ radicals attached to silicon atoms [12]. Additional absorption bands in as-deposited sample were observed at $2100 \mathrm{~cm}^{-1}\left(\mathrm{Si}-\mathrm{H}_{\mathrm{n}}\right.$ stretching $), 2700 \ldots 3000 \mathrm{~cm}^{-1}$ (C $-\mathrm{H}_{\mathrm{n}}$ stretching).

Annealing of the film in oxygen drastically changed the FTIR spectrum. FTIR spectrum is composed now of four bands, all of them are related to oxygen. The bands at $450 \mathrm{~cm}^{-1}$ (rocking), $802 \mathrm{~cm}^{-1}$ (symmetrical stretching) and $1063 \mathrm{~cm}^{-1}$ (in-phase asymmetrical stretching) with the shoulder at $1160 \mathrm{~cm}^{-1}$ (out-of-phase asymmetrical stretching) are originated from vibration modes of $\mathrm{Si}-\mathrm{O}-\mathrm{Si}$ bridges, while the very broad one at $3000 \ldots 3700 \mathrm{~cm}^{-1}$ comes from $\mathrm{O}-\mathrm{H}$ stretching vibrations. It is important to note that no sign of $\mathrm{Si}-\mathrm{C}$ related to the band at $780 \mathrm{~cm}^{-1}$ is detected after oxidation. Also, after oxidation the $\mathrm{Si}-\mathrm{H}_{\mathrm{n}}$ and the $\mathrm{C}-\mathrm{H}_{\mathrm{n}}$ bonds related correspondingly to the bands at 2100 and $2700 . .3000 \mathrm{~cm}^{-1}$ are not observed (see Fig. 2).

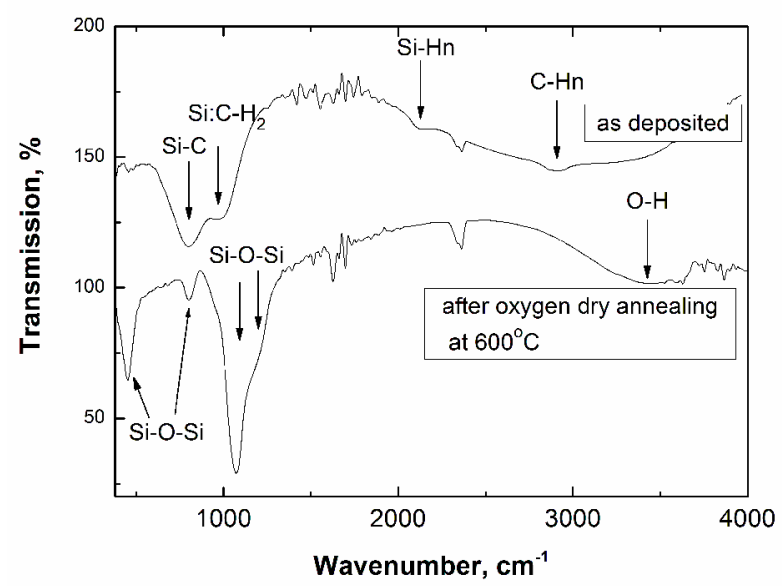

Fig. 2. FTIR spectra of the as-deposited a- $\mathrm{SiO}: \mathrm{H}(: \mathrm{Tb})$ film and after annealing in oxygen at $600{ }^{\circ} \mathrm{C}$ for $15 \mathrm{~min}$. 


\subsubsection{EELS}

An energy-loss near edge structure of the $\mathrm{Si}-\mathrm{L}_{2,3}$ spectra of the as-deposited $\mathrm{a}-\mathrm{SiO}_{1-\mathrm{x}}: \mathrm{C}_{\mathrm{x}}: \mathrm{H}(: \mathrm{Tb})$ film and after annealing in oxygen are represented in Fig. 3. The EELS spectrum of the as-deposited samples is characterized by ionization edge at about $103 \mathrm{eV}$ typical for silicon atoms bonded to carbon. Oxidation resulted in about $3 \mathrm{eV}$ highenergy shift of the ionization edge and development of two peaks at 108 and $115 \mathrm{eV}$ typical for silicon oxide [14-16]. No lower energy loss due to $\mathrm{Si}-\mathrm{C}$ bonds is now detected. Thus, this is in good agreement with FTIR data and shows that after annealing in oxygen at $600{ }^{\circ} \mathrm{C}$ the $\mathrm{a}-\mathrm{Si}_{\mathrm{x}} \mathrm{C}_{1-\mathrm{x}}$ material is transformed into $\mathrm{a}-\mathrm{SiO}_{\mathrm{x}}$.

\subsection{3. $R B S$}

The $\mathrm{Tb}$ distributions in a-Si $\mathrm{Si}_{1-\mathrm{x}} \mathrm{C}_{\mathrm{x}}: \mathrm{H}$ film before and after oxidation were measured by RBS technique and are presented in Fig. 4. Tb concentration in the film was composed about 2 at.\% and distributed enough uniformly through the film. After low temperature oxidation, the $\mathrm{Tb}$ concentration was decreased insignificantly.

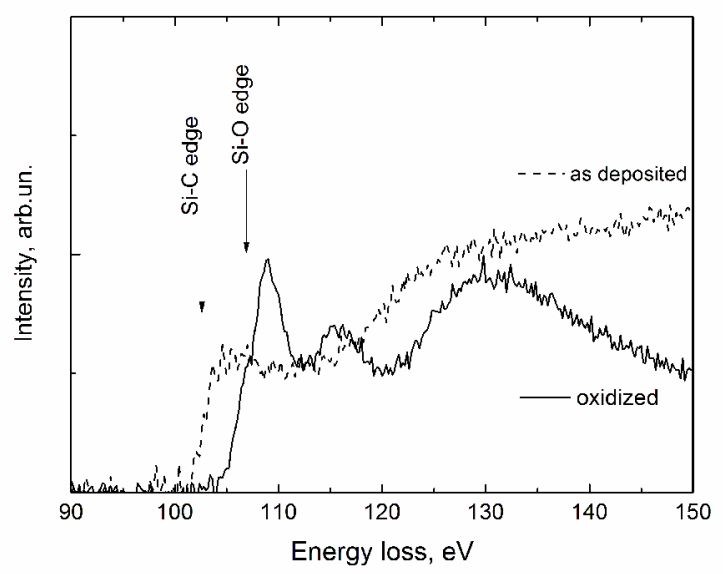

Fig. 3. Electron energy-loss near edge structure of the $\mathrm{Si}-\mathrm{L}_{2,3}$ spectra of the as-deposited a- $\mathrm{SiO}: \mathrm{H}(: \mathrm{Tb})$ film and after annealing in oxygen at $600{ }^{\circ} \mathrm{C}$ for $15 \mathrm{~min}$.

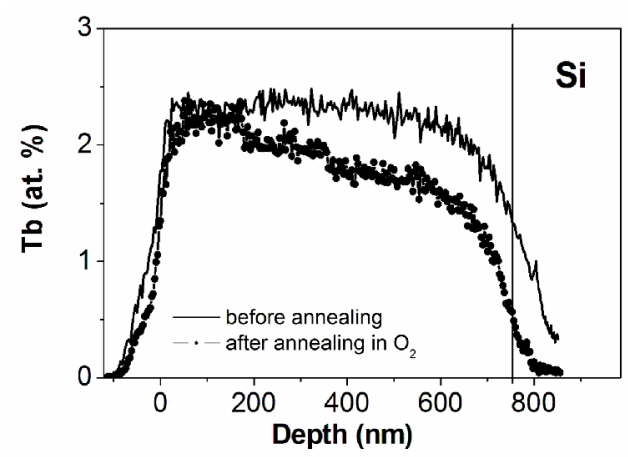

Fig. 4. Rutherford back-scattering spectra of the as-deposited a - $\mathrm{SiO}: \mathrm{H}(: \mathrm{Tb})$ film and after annealing in oxygen at $600{ }^{\circ} \mathrm{C}$ for $15 \mathrm{~min}$.

\subsection{Light-emission properties of a-SiO $\mathrm{O}_{x}: \mathrm{C}: \mathrm{Tb}$}

\subsubsection{Photoluminescence}

As-deposited a- $\mathrm{Si}_{1-\mathrm{x}} \mathrm{C}_{\mathrm{x}}: \mathrm{H}(\mathrm{Tb})$ film did not show visible luminescence, while luminescence well visible at day light under argon laser excitation was observed after oxidation (curve 1 in Fig. 5). The PL spectrum excited by the $390-\mathrm{nm}$ line of LED radiation contains four $\mathrm{Tb}^{3+}$ related lines at 488, 545, 590 and $621 \mathrm{~nm}$ and broad background in all the visible spectral range. The $\mathrm{Tb}^{3+}$ related lines correspond to intra- $4 f$ shell transitions of $\mathrm{Tb}^{3+}$ ion such as ${ }^{5} \mathrm{D}_{4}-{ }^{7} \mathrm{~F}_{6},{ }^{5} \mathrm{D}_{4}-{ }^{7} \mathrm{~F}_{5},{ }^{5} \mathrm{D}_{4}-{ }^{7} \mathrm{~F}_{4}$ and ${ }^{5} \mathrm{D}_{4}-{ }^{7} \mathrm{~F}_{3}$. The strongest line at $545 \mathrm{~nm}$ (green light) corresponds to the ${ }^{5} \mathrm{D}_{4}{ }^{7} \mathrm{~F}_{5}$ transition $[17,18]$. The nature of the wide broad PL band is unclear up to date. But it can be suggested that in green-red region the PL can be associated with amorphous carbon nanoclusters $[19,20]$ and/or carbon-related defects [21]. Some part of the PL band in blue region could be attributed to luminescence from defects located in silicon dioxide matrix such as neutral oxygen vacancies [22].

Our previous study by using the Raman scattering technique of this kind samples after low-temperature oxidation above $600{ }^{\circ} \mathrm{C}$ [20] exhibited a broad Raman scattering band within the range $1000-1800 \mathrm{~cm}^{-1}$ associated with disordered $s p^{2}$-coordinated carbon clusters. This band was a superposition of two broad Gand D-bands inherent to graphite-like local arrangement of amorphous carbon. Thus, from Raman scattering and PL measurements one can conclude that our material $\left(\mathrm{a}-\mathrm{SiO}_{\mathrm{x}}\right)$ consists of amorphous carbon nanoclusters and oxidized $\mathrm{Tb}$ inclusions which show specific lightemitting properties.

\subsubsection{Electroluminescence}

Fig. 5 demonstrates normalized EL spectra of the heterostructure for two regimes of the applied voltage. For the forward bias (curve 3), the sharp lines at 488, $545,590 \mathrm{~nm}$ were observed. These lines correspond to intra- $4 f$ shell transitions of $\mathrm{Tb}^{3+}$ ion [18]. At the reverse bias, white light emission was observed (curve 2 in Fig. 5). The spectrum can be separated into two regions. Within the spectral range $500 \ldots 650 \mathrm{~nm}$, a broad EL band is observed with a narrow $\mathrm{Tb}^{3+}$ line at $545 \mathrm{~nm}$. A broad PL spectrum in the same region was also observed in amorphous oxycarbide films fabricated by a similar procedure [23]. By analogy with Refs. [20] and [21] and our PL results described in the previous part, the origin of the broad EL band in our structure can be attributed to radiative transitions of the electronic states associated with $\mathrm{SiO}-\mathrm{C}$ bonds or carbon nanoclusters. Additionally, some contribution of the light emission associated with the excitation of non-bridging oxygen hole centers can be expected around $620 \mathrm{~nm}$ [24]. The second band covering the range from 350 up to $430 \mathrm{~nm}$ with the maximum at $370 \mathrm{~nm}$ can be associated with oxygen deficiency related centers in oxide matrix [22]. 


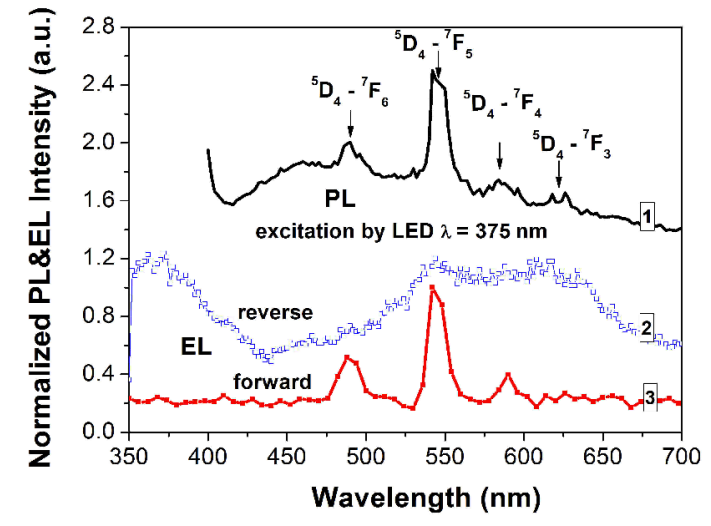

Fig. 5. Normalized photoluminescence (1) and electroluminescence intensity spectra for the forward (2) and reverse (3) biases of the $\mathrm{a}-\mathrm{SiO}_{\mathrm{x}}: \mathrm{C}: \mathrm{Tb} / \mathrm{p}-\mathrm{Si}$ heterostructure.

It should be noted that application to the structure different voltage polarity, besides of different EL spectrum, shows strongly different electric field corresponding to EL lighting (Fig. 6a), which can be associated with different potential barriers for electrical charge injection into $\mathrm{a}-\mathrm{SiO}_{\mathrm{x}}: \mathrm{C}: \mathrm{Tb}$ layer.

\subsection{Electrical properties of $a-\mathrm{SiO}_{x}: \mathrm{C}: \mathrm{Tb} / \mathrm{p}-\mathrm{Si}$ heterostructures}

\subsubsection{Capacitance-voltage characteristics}

The capacitance-voltage $(C-V)$ characteristic measured at room temperature and at a frequency of $1 \mathrm{MHz}$ for the sample annealed in oxygen at $600{ }^{\circ} \mathrm{C}$ is shown in Fig. 1. The $C-V$ characteristic has a step-like form, which is typical for metal-oxide-semiconductor (MOS) structures in the case of high frequency, featuring the plateau $C_{\max }$ at negative voltages corresponding to accumulation of majority carriers at the $\mathrm{a}-\mathrm{SiO}_{\mathrm{x}}: \mathrm{C}: \mathrm{Tb} / \mathrm{p}-\mathrm{Si}$ interface, the plateau $C_{\min }$, and deep depletion at positive gate voltages. From the magnitude of $C_{\max }$, the dielectric constant $\varepsilon$ of the a $-\mathrm{SiO}_{\mathrm{x}}: \mathrm{C}: \mathrm{Tb}$ layer was determined as 7.5, that is larger than for $\mathrm{SiO}_{2}$ film (3.9) and can be associated with terbium oxide clusters incorporation into $\mathrm{a}-\mathrm{SiO}_{\mathrm{x}}$ : C film having a high dielectric constant (near 13.3) [25].

\subsubsection{Current transport through $a-\mathrm{SiO}_{x}: \mathrm{C}: \mathrm{Tb}$}

Fig. 6 shows ELI at $545 \mathrm{~nm}$ versus the applied electric field $(E)$ and the $I-E$ dependence for the forward and reverse biases. For the forward bias, the $I-E$ characteristic exhibits three regions of current transport (see inset Fig. 6b). Up to $0.1 \mathrm{MV} / \mathrm{cm}$, the current dependence on the electric field is linear; within the range between 0.1 to $0.5 \mathrm{MV} / \mathrm{cm}$, the current shows a power low relationship $\left(J \sim E^{n}\right)$ with $n=3$; above $1 \mathrm{MV} / \mathrm{cm}$, the current has an exponential dependence on the electric field. At electric fields above $1 \mathrm{MV} / \mathrm{cm}$, EL was also observed.
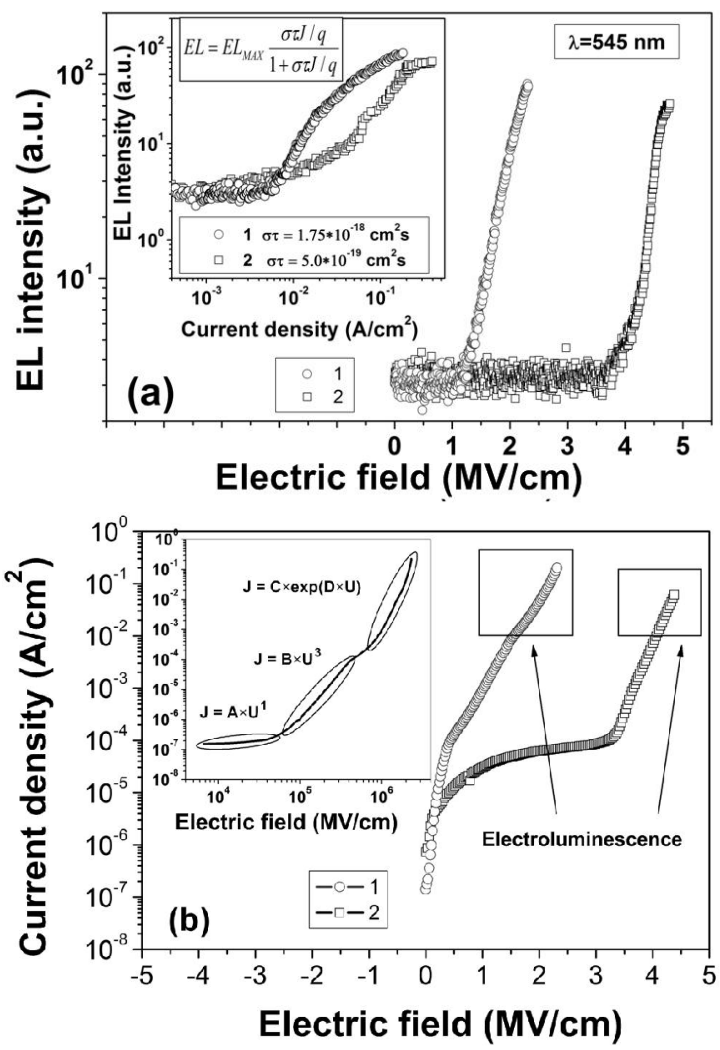

Fig. 6. (a) Dependence of the electroluminescence intensity at $545 \mathrm{~nm}$ vs. the electric field applied to the $\mathrm{a}-\mathrm{SiO}_{\mathrm{x}}: \mathrm{C}: \mathrm{Tb}$ layer for the forward (1) and reverse (2) biases. Inset: Dependence of the electroluminescence intensity vs. current density. (b) Current vs. electric field applied to the a$\mathrm{SiO}_{\mathrm{x}}: \mathrm{C}: \mathrm{Tb}$ layer for the forward (1) and reverse (2) biases. Inset: Current vs. electric field applied to the $\mathrm{a}-\mathrm{SiO}_{\mathrm{x}}: \mathrm{C}: \mathrm{Tb}$ layer for the forward bias in $\log -\log$ coordinates.

In the reverse bias regime, the $I-V$ curve consists of two regions. In the $0 \ldots 3 \mathrm{MV} / \mathrm{cm}$ region, the current varies linearly with the electric field, which is indicative of ohmic type conduction. This type of current transport can be due to a hopping mechanism where current is carried by thermally excited electrons moving between isolated discrete defect states [26]. Above $\sim 4 \mathrm{MV} / \mathrm{cm}$, the relatively high leakage current was observed. For the reverse bias regime, EL is observed at high electric fields (above $4 \mathrm{MV} / \mathrm{cm}$ ), when the leakage current exponentially depends on the electric field in this material.

\section{Discussion}

The current vs. electric field dependence have different behaviour for forward and reverse biases. For the forward bias, current changes are first linear, then cubic and exponential vs. electric field (inset to Fig. 6b). The cubic power law at high electric field following on a linear dependence at low electric field is indicative of different cases of the space charge limited current (SCLC) [27]: 
i) unipolar injection in semiconductors and dielectrics with exponentially distributed shallow traps. In this case, the current vs. voltage dependence is described as:

$J=K \frac{V^{m+1}}{L^{2 m+1}}$,

where

$m=\frac{T_{t}}{T}$,

$K=N_{c} e \mu_{n}\left(\frac{\varepsilon_{s} m}{N_{t}(m+1)}\right)^{m}\left(\frac{2 m+1}{m+1}\right)^{m+1}$,

$\mathrm{N}_{t}(E)=\frac{N_{t}}{k T_{t}} \exp \left(\frac{E-E_{c}}{k T}\right)$

$L$ being the thickness of the film, $T$ is the temperature of the sample, $N_{c}$ - effective density of states, $\mu_{n}, \varepsilon_{n}$ - charge mobility and dielectric permittivity of the film, $N_{t}$ - density of the traps, $T_{t}-$ characteristic temperature of the distribution $N_{t}(E)$ that is the density of trapping states at the energy $E$;

ii) bipolar double injection in semiconductors and dielectrics when $L / L_{a}<20$, where $L_{a}$ is ambipolar diffusion length, $L-$ thickness of the film:

$J \sim V^{2 /\left[1-l\left(L_{a} / L\right)\right],}$
$J \sim V^{3 /\left[1-l\left(L_{a} / L\right)\right],}$,

where $l$ is a constant close to 2...3. Expression (2a) is used for semiconductors and $(2 b)$ - for dielectrics.

Exponential growth of the current in SCLC model is observed in the following cases:

i) bipolar SCLC in semiconductors and dielectrics at a high voltage and large ambipolar length $-L / L_{a}<12$.

ii) unipolar SCLC in semiconductors and dielectrics with uniform energy traps distribution

$J=2 e n_{0} \mu \frac{V}{L} \exp \frac{2 \varepsilon V}{N_{n} k T e L^{2}}$,

$N_{t}(E)=N_{n}=$ const

So, for the forward bias the current transport through the oxide is determined by SCLC mechanism. As it can be seen, the exact determination of the type of SCLC and corresponded EL excitation mechanism in the forward bias regime is complicated by different mechanisms that have similar current-voltage behaviour. To accurately determine the current transport mechanism, we need to carry out current vs. temperature measurements. But we try to suggest possible mechanisms for EL excitation based on SCLC measurements. In the case of bipolar injection, electrons from the metal gate and holes from silicon injected into the $\mathrm{a}-\mathrm{SiO}_{\mathrm{x}}: \mathrm{C}: \mathrm{Tb}$ film (Fig. 8a, process 1) recombine on defects of the dielectric matrix with subsequent energy transfer to $\mathrm{Tb}^{3+}$ ions (Fig. 8a, processes 2,3 ). We can suggest that terbium ions are localized on the ways of electron-hole transport.
In the case of unipolar injection, motion of holes from silicon is complicated (probably by high energy barrier or lack of states in the band-gap near valence band), electrons from the Fermi level in metal gate injected by thermally emission into $\mathrm{a}-\mathrm{SiO}_{\mathrm{x}}: \mathrm{C}: \mathrm{Tb}$ layer conduction band with subsequent trapping in exponentially or uniform energy distributed states. However, in case of unipolar SCLC no light emission has to be observed. Thus, we can conclude that in our case of the forward applied bias bipolar double injection takes place.

For the reverse bias at high electric field (above $4 \mathrm{MV} / \mathrm{cm}$ ), the leakage current exponentially depends on the electric field in material (Fig. 6b). Such a strong dependence on the electric field is indicative of FowlerNordheim (FN) or trap assisted tunneling (TAT) of electrons through a triangle barrier as it has been shown to be the case in most of the dielectrics at high fields $[26,28]$. The current density of FN tunneling may be expressed as

$J_{\mathrm{FN}}=\frac{q^{2}}{8 \pi^{2} \hbar \varphi_{b}} E^{2} \exp \left(-\frac{8 \sqrt{2 q m^{*}}}{3 \hbar E} \varphi_{b}^{3 / 2}\right)$,

where $\varphi_{b}$ is the barrier height, $m^{*}$ - electron effective mass. The plot of $\ln \left(J / E^{2}\right)$ versus $1 / E$ in Fig. 7 shows a linear relationship. With an assumption of $m^{*}=0.52 m_{0}$, the barrier height between the a $-\mathrm{SiO}_{\mathrm{x}}: \mathrm{C}: \mathrm{Tb}$ film and silicon wafer was determined as $1.41 \mathrm{eV}$ from the slope of the $\ln \left(J / E^{2}\right)-1 / E$ dependence. It is known that the barrier height for electrons in $\mathrm{a}_{-} \mathrm{SiO}_{2}$ is from 2.8 to $3.1 \mathrm{eV}[29,30]$. The determined small value of the barrier height for electrons allows to suggest that in our case the TAT process takes place. The TAT process through a triangle barrier is described by the expression similar to (4):

$J_{T A T} \sim \exp \left(-\frac{8 \sqrt{2 q m^{*}}}{3 \hbar E} \Phi_{t}^{3 / 2}\right)$.

According to this relationship, the trap energy level $\Phi_{t}$ can be found from the plot of $\ln (J)$ versus $1 / E$ (see inset in Fig. 7), and for our case it equals to $0.86 \mathrm{eV}$. Energetic hot electrons, probably, outgo from the channels where terbium ions are located and excite mainly carbon related defects and $\mathrm{C}-\mathrm{Si}-\mathrm{O}$ bonds by direct impact ionization (Fig. 8b), which results in light emission in a wide spectral range.

The influence of the excitation mechanisms on the effective excitation cross-section $\sigma$ for Tb luminescence can be estimated from the ELI - current density characteristic for the forward and reverse regimes of the device operation (see inset Fig. 6a). If we take into account the equality of the effective electron lifetime $\tau$ for both regimes of operation, it is possible to conclude that in the case of SCLC the excitation cross-section for $\mathrm{Tb}$ is at least by a factor of four higher than in the case of impact excitation. 


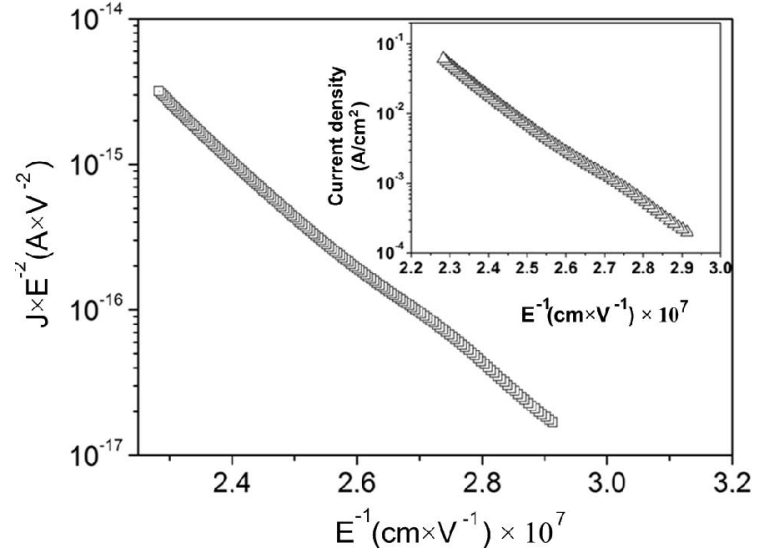

Fig. 7. Dependence of the current density vs. electric field in Fowler-Nordheim coordinates for the reverse bias at which EL is observed. Inset: Dependence of the current density vs. electric field in the TAT coordinates reverse bias.

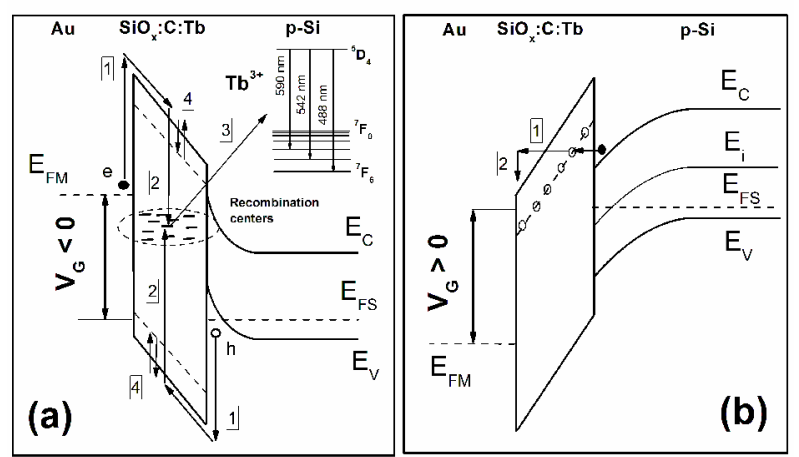

Fig. 8. Energy band-gap diagrams of the $a-\mathrm{SiO}_{\mathrm{x}}: \mathrm{C}: \mathrm{Tb} / \mathrm{p}-\mathrm{Si}$ heterostructure at the applied forward (a) and reverse (b) biases. $E_{\mathrm{F} S}$ is the Fermi level in p-Si semiconductor, $E_{\mathrm{F} M}-$ Fermi level Au metal, $V_{G}-$ gate bias. In Fig. 8a process 1 is electron and 2 - hole emission, respectively, from metal and silicon into silicon oxycarbide; 3 - electrons or holes exchange between conduction or valance bands and traps; 4 - electronhole recombination on levels in the band gap with energy transfer to $\mathrm{Tb}^{3+}$ ions; process 5 - light emission. In Fig. $8 \mathrm{~b}$ process 1 corresponds to high-field electron tunneling from $\mathrm{Si}$ inversion layer into the conduction band of silicon oxycarbide by either Fowler-Nogdheim effect or trap assisted tunneling; process 2 is the energy scattering of electrons by luminescent centers with excitation of these centers and following light emission.

The question why excitation of centers corresponding to green or white EL is different for forward and reverse biases is unclear. Diversity of EL for forward and reverse biases can be attributed to energy or space separation charge delivery to EL centers. Energy separation reaches by different charge transport: SCLC for forward bias, and TAT for reverse bias. In Ref. [23], it was demonstrated that in this material perpendicular to substrate plane high conductive carbon channels was created. If this channel disposition mainly near surface of the film and $\mathrm{Tb}^{3+}$ ions placed across the carbon channels for this kind of space separation is realized. For the forward bias, electrons transfer energy mainly to $\mathrm{Tb}^{3+}$ ions (Fig. 8a) and haven't enough energy to excite "white" centers. In the opposite case, for the applied reverse bias, electrons excite mainly "white" centers and partially the "green" ones.

\section{Conclusions}

In conclusion, an $\mathrm{a}-\mathrm{SiO}_{\mathrm{x}}: \mathrm{C}: \mathrm{Tb}$-based polarity controlled white-green light-emitting device has been fabricated. The different EL colours relates to different mechanisms of charge transport: white EL due to impact excitation of carbon-related bonds and defects by hot electrons and green EL due to the double injected space charge limited current.

\section{Acknowledgements}

We would like to appreciate Dr. Yu. Ishikawa (Japan Fine Ceramic Center, Nagoya, Japan) and Prof. Sh.Muto (Nagoya University, Japan) for the opportunity of FTIR and EELS measurements.

\section{References}

1. D.J. Lockwood, L. Pavesi, Silicon Photonics. Springer, New York, 2004.

2. J.M. Shainline, J. Xu, Silicon as an emissive optical medium // Laser \& Photon. Rev. 1, No. 4, p. 334 348 (2007).

3. S. Pruchnal, J.M. Sun, W. Skorupa, M. Helm, Switchable two-color electroluminescence based on a Si metal-oxide-semiconductor structure doped with Eu // Appl. Phys. Lett. 90, 181121 (2007).

4. S. Kuai, A. Meldrum, Rapid color-switching microLEDs from silicon MIS diodes // Physica E, 41, p. 916-920 (2009).

5. Z. Liu, J. Huang, P.C. Joshi, A.T. Voutsas, J. Hartzell, F. Capasso, J. Bao, Polarity-controlled visible/infrared electroluminescence in $\mathrm{Si}$ nanocrystal/Si light-emitting devices // Appl. Phys. Lett. 97, 071112 (2010).

6. A. Karakuscu, R. Guider, L. Pavesi, G.D. Sorarù, White luminescence from Sol-Gel-derived SiOC thin films // J. Amer. Ceram. Soc. 92, p. 2969-2974 (2009).

7. Yi Ding, Hajime Shirai, White light emission from silicon oxycarbide films prepared by using atmospheric pressure microplasma jet // J. Appl. Phys. 105, 043515 (2009).

8. Yi Ding, Hajime Shirai, Deyan He, White light emission and electrical properties of silicon oxycarbide-based metal-oxide-semiconductor diode // Thin Solid Films, 519, p. 2513-2515 (2011).

9. S. Gallis, M. Huang, Al.E. Kaloyeros, Efficient energy transfer from silicon oxycarbide matrix to 
Er ions via indirect excitation mechanisms // Appl. Phys. Lett. 90, 161914 (2007).

10. C. Rau, W. Kulish, Mechanisms of plasma polymerization of various silico-organic monomers // Thin Solid Films, 249, p. 28-37 (1994).

11. H.G.P. Lewis, D.J. Edell, K.K. Gleason, PulsedPECVD films from hexamethyl-cyclotrisiloxane for use as insulating biomaterials // Chem. Mater. 12, p. 3488-3494 (2000).

12. H. Wieder, M. Cardona, R. Guarnieri, Vibrational spectrum of hydrogenated amorphous $\mathrm{SiC}$ films // Phys. Status Solidi (b), 92, p. 99-112 (1979).

13. A. Grill, D.A. Neumayer, Structure of low dielectric constant to extreme low dielectric constant SiCOH films: Fourier transform infrared spectroscopy characterization // J. Appl. Phys. 94, p. 6697-6709 (2003).

14. O. Lichtenberger, R. Schneider, J. Woltersdorf, Analyses of EELS fine structures of different silicon compounds // Phys. Status Solidi (a), 150, p. 661-672 (1995).

15. L.A.J. Garvie, P.R. Buseck, Bonding in silicates; investigation of the $\mathrm{Si}-\mathrm{L}_{2,3}$ edge by parallel electron energy-loss spectroscopy // Amer. Mineralogist, 84, p. 946-961 (1999).

16. E. Pipel, O. Lichtenberger, J. Woltersdorf, Identification of silicon oxycarbide bonding in $\mathrm{Si}$ C-O-glasses by EELS // J. Mater. Sci. Lett. 19, p. 2059-2060 (2000).

17. H. Amekura, A. Eckau, R. Carius, and Ch. Buchal, Room-temperature photoluminescence from $\mathrm{Tb}$ ions implanted in $\mathrm{SiO}_{2}$ on $\mathrm{Si} / /$ J. Appl. Phys. 84, p. 3867-3873 (1998).

18. J.M. Sun, W. Skorupa, T. Dekorsy, M. Helm, L. Rebohle, T. Gebel, Bright green electroluminescence from $\mathrm{Tb}^{3+}$ in silicon metal-oxidesemiconductor devices // J. Appl. Phys. 97, 123513 (2005).

19. O. Gonzalez-Varona, A. Perez-Rodriguez, B. Garrido, C. Bonafos, M. Lopez, J.R. Morante, J. Montserrat, R. Rodriguez, Ion beam synthesis of semiconductor nanoparticles for $\mathrm{Si}$ based optoelectronic devices // Nucl. Instrum. and Meth. in Phys. Res. B, pp. 161-163, 904-908 (2000).
20. Y. Ishikawa, A.V. Vasin, J. Salonen, S. Muto, V.S. Lysenko, A.N. Nazarov, N. Shibata, and V.P. Lehto, Color control of white photoluminescence from carbon-incorporated silicon oxide // J. Appl. Phys. 104, 083522 (2008).

21. L. Rebohle, T. Gebel, H. Fröb, H. Reuther, W. Skorupa, Ion-beam processing for $\mathrm{Si} / \mathrm{C}$ rich $\mathrm{SiO}_{2}$ layers: Photoluminescence and microstructure // Appl. Surf. Sci. 184, p. 156-161 (2001).

22. L. Skuja, Optically active oxygen-deficiencyrelated centers in amorphous silicon dioxide // J. Non-Cryst. Solids, 239, p. 16-48 (1998).

23. S.O. Gordienko, A.N. Nazarov, A.V. Rusavsky, A.V. Vasin, Yu.V. Gomeniuk, V.S. Lysenko, V.V. Strelchuk, A.S. Nikolenko, and S. Ashok, Influence of oxidation temperature on photoluminescence and electrical properties of amorphous thin film SiC:H:O+Tb // Phys. Status Solidi (c), 8, p. 27492751 (2011)

24. C. Itoh, T. Suzuki, N. Itoh, Luminescence and defect formation in undensified and densified amorphous $\mathrm{SiO}_{2} / /$ Phys. Rev. B, 41, p. 3794-3799 (1990).

25. D. Xue, K. Betzler, and H. Hesse, Dielectric constants of binary rare-earth compounds // J. Phys.: Condens. Matter, 12, p. 3113-3118 (2000).

26. R. Perera, A. Ikeda, R. Hattori, Y. Kuroki, Trap assisted leakage current conduction in thin silicon oxynitride films grown by rapid thermal oxidation combined microwave excited plasma nitridation // Microelectron. Eng. 65, p. 357-370 (2003).

27. M.A. Lampert and P. Mark, Current Injection in Solids. Academic, New York, 1970.

28. S.M. Sze, Physics of Semiconductor Devices. Wiley, New York, 1981.

29. G. Krieger, R.M. Swanson, Fowler-Nordheim electron tunnelling in thin $\mathrm{Si}-\mathrm{SiO}_{2}-\mathrm{Al}$ structures // J. Appl. Phys. 52, p. 5710-5717 (1981).

30. Z.N. Weinberg, On tunnelling in metal-oxidesilicon structures // J. Appl. Phys. 53, p. 5052-5056 (1982). 